\title{
NLRP3 Inflammasome: Activation and Regulation in Age-Related Macular Degeneration
}

\author{
Jiangyuan Gao, Ruozhou Tom Liu, Sijia Cao, Jing Z. Cui, Aikun Wang, \\ Eleanor To, and Joanne A. Matsubara \\ Department of Ophthalmology and Visual Sciences, Faculty of Medicine, University of British Columbia, \\ Vancouver, BC, Canada V5Z 3N9 \\ Correspondence should be addressed to Joanne A. Matsubara; jms@mail.ubc.ca
}

Received 19 September 2014; Accepted 15 December 2014

Academic Editor: Benedicte Py

Copyright (C) 2015 Jiangyuan Gao et al. This is an open access article distributed under the Creative Commons Attribution License, which permits unrestricted use, distribution, and reproduction in any medium, provided the original work is properly cited.

\begin{abstract}
Age-related macular degeneration (AMD) is the leading cause of legal blindness in the elderly in industrialized countries. AMD is a multifactorial disease influenced by both genetic and environmental risk factors. Progression of AMD is characterized by an increase in the number and size of drusen, extracellular deposits, which accumulate between the retinal pigment epithelium (RPE) and Bruch's membrane (BM) in outer retina. The major pathways associated with its pathogenesis include oxidative stress and inflammation in the early stages of AMD. Little is known about the interactions among these mechanisms that drive the transition from early to late stages of AMD, such as geographic atrophy (GA) or choroidal neovascularization (CNV). As part of the innate immune system, inflammasome activation has been identified in RPE cells and proposed to be a causal factor for RPE dysfunction and degeneration. Here, we will first review the classic model of inflammasome activation, then discuss the potentials of AMDrelated factors to activate the inflammasome in both nonocular immune cells and RPE cells, and finally introduce several novel mechanisms for regulating the inflammasome activity.
\end{abstract}

\section{Introduction}

Age-related macular degeneration (AMD) is a neurodegenerative disease characterized by the deterioration of photoreceptors in the macula, a specialized region of the retina responsible for fine visual acuity that is required for tasks such as reading, facial recognition, and driving [1]. According to the World Health Organization, AMD currently ranks as the third global leading cause of blindness, second only to cataract and glaucoma [2]. However, among the elderly, AMD is the most common cause of irreversible vision loss in developed countries. Approximately 30-50 million individuals worldwide are afflicted with AMD. The economic costs for treatment and care of individuals who suffer vision loss from AMD are projected to be more than US $\$ 300$ billion annually, a heavy toll that will significantly impact global social and public health systems and one that prompts an urgent need to decipher its underlying mechanisms [3].

Being a complex disease, the pathogenesis and progression of AMD are influenced by a variety of risk factors. Among them, advanced chronologic aging is thought to be the strongest [4-6]. The prevalence of AMD steadily increases with age, affecting $2 \%$ of the population at age 40 and $25 \%$ by age 80 [7]. Besides aging, other risk factors such as cigarette smoking and diet also contribute to the development of the disease [8-11]. Clinically, early stages of AMD are defined by the presence of drusen, the extracellular deposits located between the retinal pigment epithelium (RPE) and Bruch's membrane (BM) (Figure 1). Despite the fact that early AMD is usually not associated with appreciable vision loss, the number and the size of drusen deposits serve as signs of disease progression [12]. When the disease progresses into the late stage, it takes one of two forms: geographic atrophy (GA), featured by confluent regions of RPE and photoreceptor degeneration, and choroidal neovascularization (CNV), characterized by the abnormal growth of leaky choroidal vessels invading retina. Initially considered a supporting cell in the outer retina, RPE are active in a wide range of biological processes that maintain local homeostasis. These processes include recycling components of the visual cycle, secreting trophic factors, controlling cross-epithelium transport, and maintaining the outer blood-retinal barrier $[13,14]$. Central to 

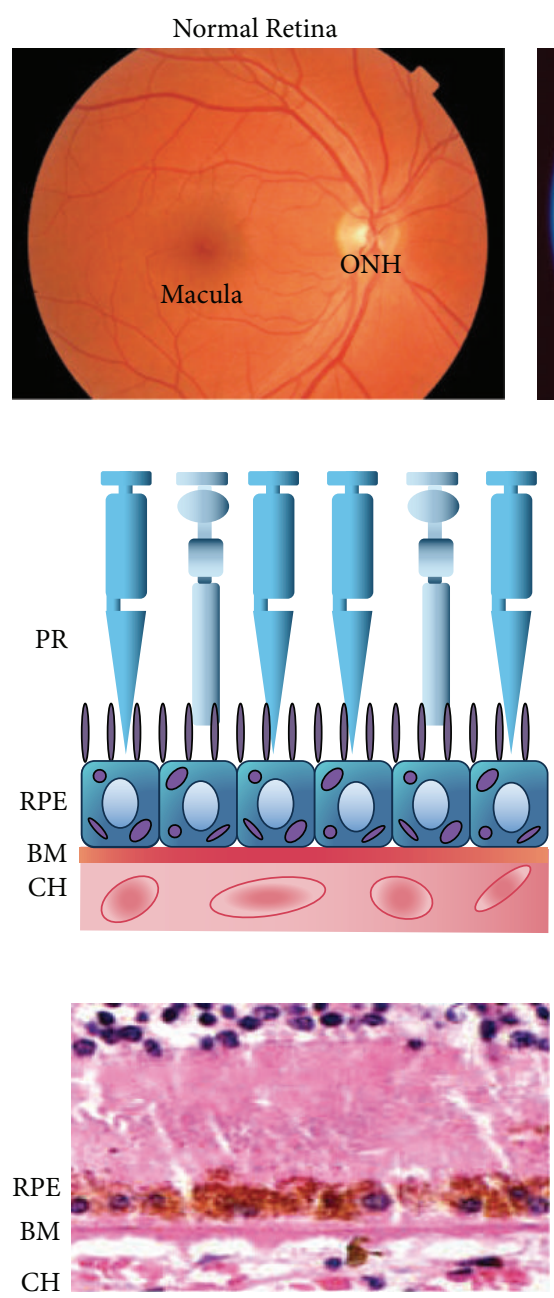

Early AMD

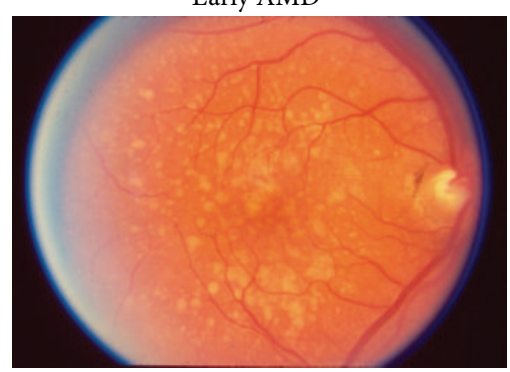

(a)

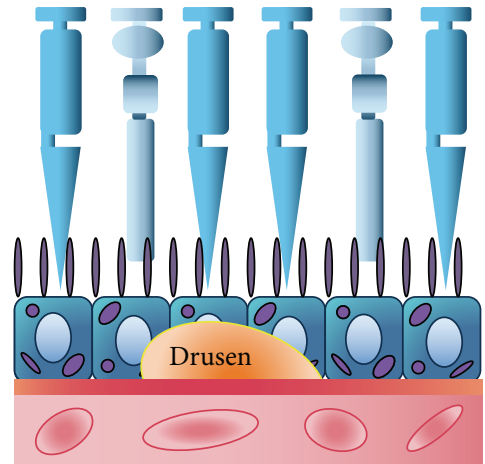

(b)

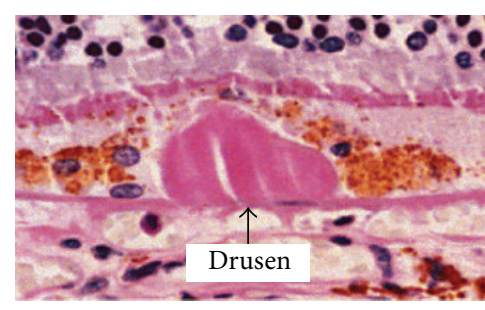

(c)
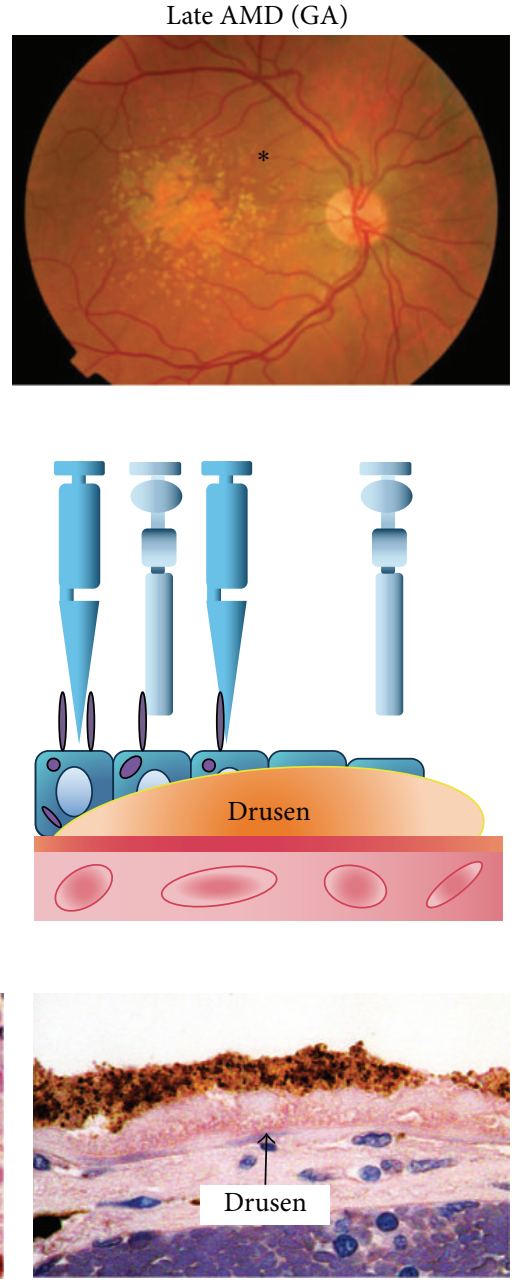

FIGURE 1: Clinical stages and signs of age-related macular degeneration. (a) Fundus photos demonstrate clinical features of AMD at different stages. Early AMD shows yellow extracellular drusen deposits surrounding macular area. Late AMD (GA) shows hypopigmentation or background darkening $(*)$ around drusen. A large number of drusen deposits are observed accumulated in the macular area. (b) Schematic diagram of drusen accumulation and RPE/photoreceptor degeneration from early to late stage AMD (GA). (c) Staining of human postmortem donor eye tissues depicting normal, early AMD, and late AMD. Arrows point to different forms of drusen: a large hard drusen in an early AMD eye and a diffuse, soft drusen in a late AMD (GA) eye. GA, geographic atrophy; ONH, optic nerve head; PR, photoreceptors; RPE, retinal pigment epithelium; $\mathrm{BM}$, Bruch's membrane; $\mathrm{CH}$, choroidal capillaries.

AMD pathogenesis, the RPE undergoes significant changes in structure and function that predispose individuals to disease processes associated with AMD. Suggestive of an associated, and perhaps causal, role in RPE dysfunction is the finding that RPE cells overlying drusen appear swollen and vacuolated [15]. It is further proposed that the spontaneous release of drusen components during drusen regression in AMD development may result in RPE loss in GA [16].

\section{NLRP3 Inflammasome}

Recent advances have highlighted the essential role of immune processes in the development, progression, and treatment of AMD [1]. Both the innate and adaptive immune systems have been shown to contribute to AMD pathogenesis (for reviews, see $[28,29]$ ). The innate immune system is an evolutionarily conserved system that constitutes the first line of defense against pathogens. Inflammasome activation is a key component of innate immunity, which when overactive has been linked with many human immune diseases [30-33]. The inflammasome is an intracellular, multiprotein complex whose molecular composition is stimulus dependent. The canonical inflammasome complexes are assembled around protein members of the nod-like receptor (NLRs) or HIN200 protein families, converting the procaspase-1 zymogen into a catalytically active enzyme. The inflammasome family is further categorized based on the presence of an apoptosisassociated speck-like protein containing a caspase recruitment domain (ASC). The canonical inflammasome can be further categorized into ASC-dependent (NLRP3 and AIM2) 
and ASC-independent (NLRP1 and NLRC4) subtypes [34]. The noncanonical inflammasome complex with an, as yet, unknown structural composition is proposed to promote the activation of caspase-11 [35]. Despite the gap in knowledge of the structure of the noncanonical inflammasome, there is a wealth of evidence to firmly establish the mode of action for several canonical inflammasomes in the immune signaling pathway, especially the most widely studied NLRP3 inflammasome [36].

The NLRP3 inflammasome senses and responds to a diversity of pathogen- or danger-associated molecular patterns (PAMPs or DAMPs), including bacterial/viral/fungal pathogens, pore-forming toxins, uric acid crystals, particulate aggregates, and adenosine triphosphate (ATP). To be activated, the NLRP3 inflammasome requires the presence of two signals, a "priming signal" and an "activation signal," both of which are vital to control the degree of immune response driven by the products of inflammasome activation. In most cases, the "priming signal" channels through the nuclear factor kappa B (NF- $\kappa$ B) pathway, upregulating the transcription of NLRP3 and prointerleukin-1 $\beta$ (pro-IL-1 $\beta$ ) [37]. It is a fact that, in both immune and RPE cells, pro-IL-1 $\beta$ is not constitutively expressed and the endogenous level of NLRP3 appears to be inadequate for inflammasome activation, thus making the priming process critical $[17,38]$. In contrast, other inflammasome-related proteins, ASC, procaspase-1, and pro-IL-18, are constitutively expressed in RPE cells and therefore priming may, or may not, further increase their protein levels $[17,20,39,40]$. In addition to the classic, transcription-dependent priming, it is now known that NLRP3 inflammasome can be "primed" posttranslationally, adding another layer of regulation [41]. Common priming signals for immune cells of the body and human RPE cells are lipopolysaccharide (LPS), tumor necrosis factor- $\alpha$ (TNF- $\alpha$ ), nitric oxide, and IL- $1 \alpha[17,42]$. In the presence of foreign or endogenous "activation signals," NLRP3 senses one or more of the following intracellular changes: $\mathrm{K}^{+}$efflux [43], release of lysosomal resident cathepsin B [44], overproduction of reactive oxygen species (ROS) [45], NLRP3 translocation to mitochondria [46], cell volume change, and $\mathrm{Ca}^{2+}$ disequilibrium [42]. Once the NLRP3 is activated, it recruits ASC and mediates the proximity-induced procaspase-1 autoactivation. The assembled NLRP3 inflammasome then turns itself into a cytokine processing platform by cleaving pro-IL- $1 \beta /$ pro-IL18 into mature peptides and releasing them into extracellular space for downstream effects (Figure 2). Of note, the generalized NLRP3 inflammasome activation process summarized above is much simpler than what actually happens in a given cell. Further discussion on NLRP3 inflammasome regulation will be provided in Section 4 .

\section{NLRP3 Inflammasome Activators Relevant to AMD}

More recently, the role of the NLRP3 inflammasome in AMD pathogenesis has been extensively investigated using AMD related stimuli. Being a hallmark of AMD progression, drusen has a rich proteinaceous composition, including complement regulators, amyloid-beta $(\mathrm{A} \beta)$, and oxidation by-products $[15,47-54]$, which makes drusen components ideal triggers for potential interactions with the NLRP3 inflammasome.

3.1. Complement Factors. As part of the innate immunity, the complement system is one of the first that responds to tissue damage during aging and is activated by cell death [55]. In this regard, stressed, damaged, or dying RPE could trigger local complement activation, which is supported by the fact that activated complement components as well as complement regulators are present in drusen. The degree of complement activation is precisely regulated in healthy retina and is thus beneficial for tissue homeostasis and longevity. However, when the complement system is in overdrive due to either genetic polymorphisms [56] or chronic, sustained pathological stimulation, it generates undesirable amounts of activated complement factors, facilitates the formation of terminal membrane attack complex (MAC), and thus advances AMD pathology [57]. To bolster this notion, Doyle and colleagues have showed that drusen extracts isolated from AMD donor eye tissues are able to activate the NLRP3 inflammasome in LPS-primed macrophages [18]. They further revealed the role of complement factor $1 \mathrm{q}(\mathrm{Clq})$ as an NLRP3 inflammasome "activation signal" by showing caspase-1 cleavage and elevated IL-1 $\beta$ secretion after Clq stimulation on LPS-primed mouse bone marrow derived macrophages and THP1 human monocytic cells. Moreover, in addition to Clq stimulation, other studies have suggested complement factor $3 \mathrm{a}(\mathrm{C} 3 \mathrm{a})$ and MAC may also mediate the activation of the inflammasome, further linking many components of the complement pathway with IL- $1 \beta$ and IL- 18 production $[24,25,58]$ by unique underlying mechanisms. For instance, sublytic MAC is known to activate NLRP3 inflammasome through $\mathrm{Ca}^{2+}$ influx and/or $\mathrm{K}^{+}$efflux, whereas C3a activation of the NLRP3 inflammasome is initiated by the release of ATP into the extracellular space. These studies were primarily conducted on monocytes, dendritic cells, or lung epithelial cells. Although the aforementioned mechanisms are yet to be confirmed in AMD models, they do lend to the biological plausibility that similar processes can happen in ocular tissue. We recently tested the systemic administration of a small molecular inhibitor for MAC, aurintricarboxylic acid complex (ATAC), on NLRP3 inflammasome activation in rat RPE/choroid tissues at different ages. We found that ATAC suppressed the age-dependent increase in MAC formation and caspase-1 cleavage (a prominent indicator for NLRP3 inflammasome activation) in RPE/choroid tissue homogenates, which implies potential benefits by targeting MAC formation in AMD pathogenesis (Figure 2).

3.2. Amyloid-Beta. Amyloid-beta $(\mathrm{A} \beta)$ is a drusen component found in AMD eyes [51, 59, 60]; more recently there is growing interest in $\mathrm{A} \beta$ for its capacity to stimulate inflammasome activation and potentially contribute to AMD pathogenesis. As a pathological peptide best known for its neurotoxicity in Alzheimer's disease (AD), $\mathrm{A} \beta$ is generated through the amyloidogenic pathway by cleaving the amyloid precursor protein (APP) into the intramembrane $\mathrm{A} \beta$ domain of 36-43 amino acids in length [61]. The accumulation of $A \beta$ 


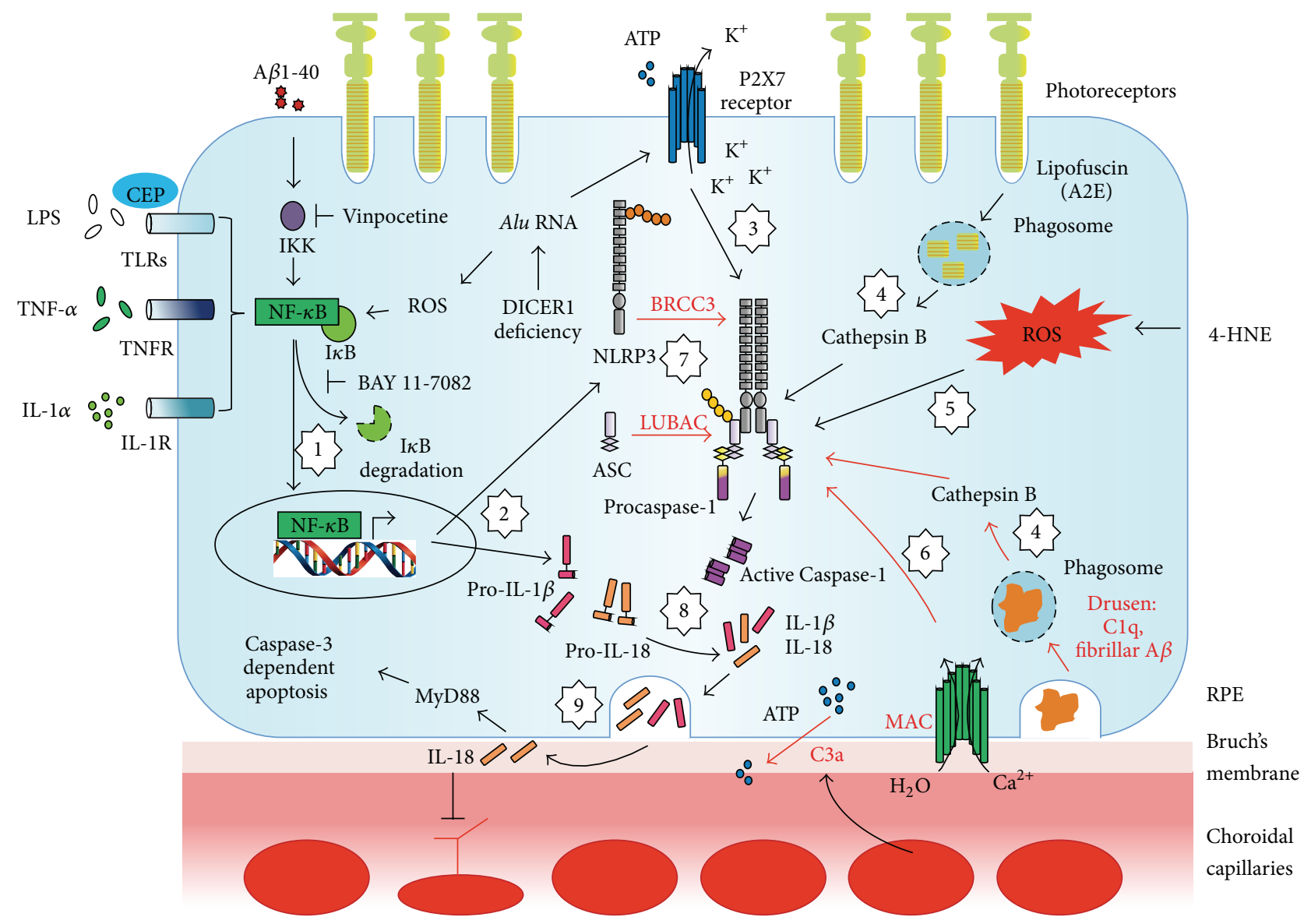

FIGURE 2: Current model of NLRP3 inflammasome activation in RPE. (1) Priming of the RPE by one of the following factors (LPS [17], TNF- $\alpha$ [17], IL-1 $\alpha$ [17], CEP [18], and A $\beta 1-40$ [19]) is needed in order to activate the NF- $\kappa$ B pathway, which can be specifically blocked by vinpocetine or BAY 11-7082 [19]. Intriguingly, DICER1 deficiency induced Alu RNA accumulation has also been demonstrated to prime NF- $\kappa$ B signaling, independent of toll-like receptors (TLRs) [20]. (2) Once the NF- $\kappa$ B pathway is active, it promotes the transcription of NLRP3 and pro-IL-1 $\beta$. (3-7) For the production of mature IL-1 $\beta$ and IL-18; separate inflammasome components are assembled as a multiprotein complex triggered by one of the following mechanisms: $\mathrm{K}^{+}$efflux via P2X7 receptor activation in response to extracellular ATP accumulation or intracellular Alu RNA [20] (3); cytoplasmic cathepsin B release from destabilized phagolysosomes of lipofuscin/A2E [21] (4); ROS overproduction caused by 4-HNE [22] (5). Other NLRP3 inflammasome activation mechanisms that have been reported in immune cells but not validated in RPE cells are shown in red text and arrows. These include drusen components (Clq [18] and fibrillar A $\beta$ [23]) induced lysosomal damage (4), C3a triggered ATP efflux [24], MAC formation [25] (6), BRCC3-mediated deubiquitylation [26], and LUBAC-mediated ubiquitylation [27] (7). (8) Successful assembly of NLRP3 inflammasome triggers autoproteolysis of procaspase-1 into active caspase-1, which further oligomerizes to convert pro-IL-1 $\beta$ and pro-IL-18 into bioactive peptides. (9) The biological significance of NLRP3 inflammasome activation is to release active IL-1 $\beta$ and IL-18 into extracellular space through exocytosis. The secreted IL- $1 \beta$ will facilitate inflammation process in the tissue whereas IL-18 will either promote caspase-3 dependent RPE apoptosis via MyD88 signaling or suppress neovascular vessels growth in the choroid capillaries.

in tissue results from its disturbed balance between production and clearance, the latter of which is largely controlled by the membrane-bound degradation enzyme, neprilysin [62, 63]. A $\beta$ 's intrinsic cytotoxicity lies in its aggregated forms as soluble oligomers or insoluble fibrils. Originally thought as a primary toxic structure, $\mathrm{A} \beta$ fibrillar plaques are now considered less harmful to brain neurons than the small spherical oligomers that damage cell membranes and cause cell death $[61,64-68]$. A $\beta$ 's ocular presence has been reported in studies of postmortem human donor eyes $[54,60,69]$ showing specific deposition within drusen from AMD eyes [53]. The age-dependent deposition of $\mathrm{A} \beta$ in the outer retina $[59,70]$ can be, at least partially, attributed to local RPE synthesis [51]. In this regard, transgenic animals lacking neprilysin exhibited $\mathrm{A} \beta$ accumulation in both RPE and sub-RPE deposits, concomitant with significant RPE atrophy [71]. When incubated with $\mathrm{A} \beta$ oligomers, human primary RPE cells demonstrated a prominent decrease in cell viability [72]. These findings point towards $\mathrm{A} \beta$ 's potential role in promoting RPE atrophy. Nevertheless, the exact mechanism by which $\mathrm{A} \beta$ contributes to RPE atrophy is still poorly understood but may involve inflammasome-related caspase-1 dependent cell death.

In addition to its cytotoxicity, $A \beta$ is also a major proinflammatory factor that has been extensively studied in the 
context of AMD. The presence of $\mathrm{A} \beta$ in drusen is found to overlap with complement activation sites $[47,51]$. In an RPE cell culture model, Kurji et al. discovered that inflammationassociated genes and immune response pathways were the predominant responses of RPE to oligomeric $\mathrm{A} \beta$ stimulation [72]. Proinflammatory responses to $\mathrm{A} \beta$ stimulation were also verified further in an in vivo model using intravitreal injections of $\mathrm{A} \beta$ in rodents, in which the RPE demonstrated upregulation of NLRP3, IL-1 $\beta$, and IL-18 [69]. In this intravitreal $\mathrm{A} \beta$ injection model, inflammasome activation was demonstrated by caspase- 1 cleavage, IL- $1 \beta$, and IL-18 immunoreactivity in the RPE and surrounding tissue including the vitreous, which was further suppressed by an NF$\kappa \mathrm{B}$ inhibitor, vinpocetine [19]. The secreted inflammasome effector cytokines, IL-1 $\beta$ and IL-18, are known to exert potent cytotoxic effects on RPE cells [40], which might provide a possible explanation for $\mathrm{A} \beta$ induced RPE cell death in vitro. These findings in RPE are consistent with a multitude of studies that implicate $\mathrm{A} \beta$ and NLRP3 inflammasome activation in glial cells and central nervous system disease, specifically AD. Using fibrillar $\mathrm{A} \beta$, Halle et al. reported the activation of NLRP3 inflammasome by lysosomal destabilization which increased release of IL-1 $\beta$ in murine microglia [23] (Figure 2). To further substantiate the link between inflammasome activation and the deleterious effect of $\mathrm{A} \beta$ in the brain, APP/PS1 mice with NLRP3 deficiency demonstrated improved $A \beta$ clearance by microglia and preserved memory and behavior patterns [73]. A $\beta$-induced NLRP3 inflammasome activation in glial cells may rely on activation of cathepsin family of proteases and the degradation of NLRP10 [74].

3.3. Oxidation By-Products. Having the most abundant polyunsaturated fatty acids in the eye, photoreceptors are protected by RPE cells from excessive high-energy light exposure. As part of the visual cycle, photoreceptors shed their oxidized tips of outer segments, which are then phagocytosed by RPE cells for the recycling of 11-cis-retinal. With age, the ability of RPE cells to recycle the "waste" from photoreceptors decreases significantly, leading to the accumulation of lipid peroxidation by-products, lipofuscin, in the RPE. It has been previously suggested that lipofuscin accumulation in RPE causes lysosome damage and directly triggers the formation of active NLRP3 inflammasome [17, 21, 75]. Other lipid peroxidation end products, such as 4-hydroxynonenal (HNE) and carboxyethylpyrrole (CEP), have also been shown to contribute to NLRP3 inflammasome activation [18, 22]. By incubating ARPE-19 cells, a cell line that possesses key features of human RPE cells, with HNE alone or in combination with LPS, Kauppinen et al. demonstrated a substantial increase of secreted IL-18 and IL-1 $\beta$, products of NLRP3 inflammasome activation [22]. Doyle and colleagues discovered a priming effect for CEP, which promoted IL-1 $\beta$ secretion when combined with an inflammasome "activation signal," such as ATP and C1q [18] (Figure 2). Furthermore, the recently established CEP-immunized murine model of AMD may serve as a useful platform to substantiate the role of CEP in NLRP3 inflammasome activation [76].
3.4. Genetic Variants. A disease with complex etiology, AMD, is also heavily influenced by genetic modifications. In GA patients, Kaneko et al. reported the repetitive elementderived Alu RNA transcripts as an inducer for RPE degeneration [77]. These retrotransposon elements are short interspersed nuclear elements in eukaryotic genome, containing internal promoter sequences for RNA polymerase III [78]. Thus, the Alu mobile repeats are noncanonical targets of DICER1, an evolutionarily conserved member of the RNase III nuclease family, essential for the control of microRNA biogenesis [79]. Originally considered as selfish "junk DNA" entities in the host genome, the Alu elements are now recognized for their complex regulatory functions, such as transcriptional repression [80] and modulation of alternative splicing [81], and involvement in human genetic diseases by inducing insertion mutations, DNA breaks, genome instability, and exonization $[82,83]$. It has been shown that the loss of DICER1 expression, possibly due to oxidative stress in the RPE, is responsible for the abnormal Alu repeats accumulation in GA patients [77]. These Alu transcripts function as both priming (toll-like receptors independent, TLRs) and activating (P2X7 receptor dependent) signals to stimulate NLRP3 inflammasome activation, leading to the release of IL18 and subsequent caspase-8/caspase-3 dependent apoptotic RPE death via MyD88 and/or Fas ligand mediated signaling $[20,40,84]$. These findings are novel as they provide us with a new perspective into the apoptotic RPE death mechanism underlying GA. These findings are also unique and counter intuitive at first appearance, since MyD88 is a versatile adaptor protein for the TLR/IL-1R superfamily-mediated proinflammatory signalling (reviewed in [85]), whereas apoptosis is essentially a noninflammatory cell death mechanism. Although very rare, there are cell-type specific reports connecting apoptosis with MyD88 mediated proinflammatory events, presumably as a final attempt for the tissue to remove the severely damaged cells. In pancreatic islet $\beta$ cells, Dupraz et al. showed that overexpression of a dominant negative form of MyD88 spared the cells from IL- $1 \beta$ induced apoptosis [86]. Moreover, using human kidney epithelial 293 cells and human monocytic THP-1 cells, Aliprantis and colleagues found that MyD88 was crucial to the activation of TLR2 signaling and its downstream induction of caspase- 8 dependent apoptosis in response to bacterial lipoproteins [87]. However, similar mechanisms have not been previously reported in ocular tissues or cells, including RPE, until recently.

Taken together, these lines of evidence suggest that damaged RPE cells can respond to danger signals by activating the inflammasome pathway that may further lead to RPE atrophy in GA (Figure 2).

\section{Regulation of NLRP3 Inflammasome Activity}

As a cellular property, the inflammasome is a powerful double-edged sword. Insufficient activation makes the immune system vulnerable to PAMPs and DAMPs, whereas overwhelming inflammasome activation targets the host itself. Hence, it is paramount to keep inflammasome activity in check. Clinically, inflammasome antagonists are being 
explored as novel therapeutics for treating human immune diseases $[42,88]$. The inhibition of inflammasome can potentially be achieved at four different levels along its activation pathway [42]. These include blocking cell membrane receptors (e.g., P2X7 receptor for ATP), controlling cytoplasmic second messengers (e.g., $\mathrm{K}^{+}$, cathepsin B, ROS), preventing inflammasome components from assembling, and antagonizing released cytokine products and/or their cognate receptors. To better understand how inflammasome formation is regulated, we will review several newly discovered mechanisms.

4.1. Mitochondria and NLRP3 Inflammasome. Mitochondria, the symbolic "power house" in the cell, are also known for other biological events, including intrinsic or "mitochondrial" apoptosis and innate immune signal transduction [89]. The role of mitochondria in RPE dysfunction has previously been implicated in AMD pathogenesis [90]. In addition to lipid and protein peroxidation mentioned earlier in this review, mitochondrial DNA (mtDNA) is considered particularly prone to ROS relative to its nuclear counterpart. Research showed that when treated with hydrogen peroxide or rod outer segments human RPE cells generated more damaged and unrepaired mtDNA, leading to mitochondrial redox dysfunction, inefficient energy production, RPE dysfunction, and ultimate initiation of RPE apoptosis [90]. Moreover, it has been recently suggested that inherited mitochondrial DNA variation can also impact pathways other than apoptosis, for instance, in the complement activation [91]. By introducing mitochondria from individuals with either high- or lowrisk haplogroups (accumulations of specific single nucleotide polymorphisms) for AMD into ARPE-19 cells devoid of mtDNA, Kenney et al. were able to map the relationship between mtDNA polymorphisms and nuclear gene expression for a number of molecular pathways related to AMD. ARPE-19 cybrids (cytoplasmic hybrids with native ARPE19 cell nuclear DNA and extrinsic mtDNA) harboring highrisk mtDNA haplogroup for AMD demonstrated decreased energy production and lower gene expression levels for $\mathrm{CFH}$ and $\mathrm{C} 3$, key components of the complement pathway [92]. When confronted with sublethal ultraviolet radiation, these high-risk cybrids had a further decrease in CFH gene expression, which could potentially lead to a greater degree of complement activation [93]. As discussed in previous sections, complement activation products and MAC may act as potential triggers for inflammasome activation. However, the exact mechanisms bridging mitochondrial damage and $\mathrm{RPE}$ apoptosis remain elusive.

Bruey et al. reported a novel role of $\mathrm{Bcl}-2$ and $\mathrm{Bcl}-$ $\mathrm{xL}$, two mitochondria-associated antiapoptotic proteins, in the suppression of the NLRP1 inflammasome activation in ATP stimulated macrophages [94]. By comparing the macrophages isolated from $\mathrm{Bcl}-2$ overexpressing transgenic mice to their wild-type counterparts, Zhou et al. showed a significant decrease of secreted IL- $1 \beta$ levels in association with the increasing Bcl-2 expression, under classic NLRP3 inflammasome activation conditions [45]. Separately, Shimada and colleagues also reported Bcl-2 attenuates NLRP3 inflammasome activity through inhibition of mtDNA release from the dysregulated and apoptotic mitochondria in macrophages [95]. However, another study using Bcl-2 overexpressing mice does not support Bcl-2's role in regulating NLRP3 inflammasome function [96]. Clearly, further investigation on the relationship between mitochondria-associated antiapoptotic proteins and NLRP3 inflammasome activation is warranted. Another example showcasing mitochondria's involvement in NLRP3 inflammasome activation comes from the studies on mitochondrial ROS, which has been proposed to be either necessary or facilitate the activation of the NLRP3 inflammasome, by two research groups, independently [45, 97]. Zhou et al. further proposed it was the dissociation between thioredoxin and thioredoxin-interacting protein (TXNIP) under ROS stimulation that allowed TXNIP to bind to NLRP3, resulting in NLRP3 conformational change and ultimate activation [98]. Moreover, the use of antioxidants to inhibit NLRP3 inflammasome activity has been extensively studied and proved effective, despite the fact that the detailed underlying signaling pathways remain unclear. Nonetheless, there is ongoing debate as to whether mitochondrial ROS only works as a facilitator of NLRP3 inflammasome activation, given the fact that increasing intracellular ROS levels can as well inhibit caspase- 1 activation and IL- $1 \beta$ maturation [99-101]. Perhaps, a more comprehensive approach, such as a model reflecting intracellular antioxidant response to mitochondrial ROS overproduction, might provide insights regarding the determinants of the level of NLRP3 inflammasome activity, taking into account that both sides of the redox axis could play a role [102].

4.2. Ubiquitylation and Deubiquitylation. Ubiquitylation is a common posttranslational modification of proteins through a cascade of enzymatic activity of ubiquitin ligases. It has multiple effects on proteasome- or lysosome-mediated protein degradation, cell signal transduction, and protein activity regulation. According to the type and length of ubiquitin linkage, there are three major forms of protein ubiquitylation currently studied, including lysine 48 (K48) linked ubiquitylation, lysine 63 (K63) linked ubiquitylation, and methionine 1 (Met 1) linked linear ubiquitylation [103]. Mounting evidence has implicated the involvement of ubiquitylation in AMD pathophysiology. By looking at the retinal distribution of several class III ubiquitin-conjugating enzymes in mice, Mirza et al. reported robust protein expression of one such enzyme, UbcM2, in murine photoreceptors and RPE cells. The authors further experimented UbcM2's protective effects on photoreceptors using an acute bright-light-damage model. It was shown that mice with only one copy of functional UbcM2 allele were protected from acute excessive light damage to photoreceptors, suggesting a strong relationship between UbcM2-mediated ubiquitylation and photoreceptor survival [104]. In human RPE cells, it is evident that there is an active ubiquitin-proteasome mediated protein degradation pathway, with low endogenous levels of ubiquitin to fight against cellular stressors [105]. In the context of AMD, Ramos de Carvalhol et al. tested the proteasome activity of primary human RPE cells in response to complement factor C3a, a known drusen component. C3a stimulation significantly reduced proteasome activity without changing its component 
at either protein or mRNA levels, indicating a potential functional suppression of the proteasome in primary human RPE [106]. On the other hand, the family of deubiquitinating enzymes (DUBs) is another force balancing protein activity. Glenn and colleagues reported altered proteomic profiling of ARPE-19 cells cultured on advanced glycation end products (AGEs, known drusen component) modified Matrigel BM extract compared to non-AGE modified control BM. Of note, by immunocytochemistry, the authors were able to localize upregulated protein expression of a DUB protein, ubiquitin carboxyterminal hydrolase-1 (UCH-L1), in AGE-stimulated ARPE-19 cells, suggesting a potential role for DUBs in AMD pathogenesis [107].

However, few reports exist on the roles of both ubiquitinating and deubiquitinating enzymes in NLRP3 inflammasome regulation. Recently, Py and colleagues demonstrated that BRCC3, a JAMM domain-containing zinc metalloprotease DUB, promotes NLRP3 inflammasome activation by deubiquitinating the mixed K64 and K48 ubiquitin chains on both the NACHT and LRR domains of NLRP3 [26]. The authors further suggested that the deubiquitylation of NLRP3 was critical for the inflammasome activation based on the facts that inhibiting BRCC3 could abolish NLRP3 inflammasome activation under a diverse range of classic “activation signals," including $\mathrm{K}^{+}$efflux, ROS overproduction, and lysosomal destabilization. Perhaps more intriguing is the report by Rodgers et al. of the discovery that the linear ubiquitylation of the ASC adaptor protein by the linear ubiquitin assembly complex (LUBAC) is also essential for NLRP3 inflammasome activation, independent of NF- $\kappa \mathrm{B}$ activity [27] (Figure 2). Clinically, these studies provide potential alternative approaches for the treatment of inflammasomerelated diseases by better controlling the ubiquitylation levels of separate NLRP3 inflammasome components, instead of targeting secreted levels of the mature proinflammatory cytokines.

\section{Concluding Remarks}

In this review, we summarize the key features of NLRP3 inflammasome activation and introduce newly discovered regulatory mechanisms. We also discuss the involvement of NLRP3 inflammasome in the pathogenesis of AMD, with the focus on individual drusen components as potential facilitators for NLRP3 inflammasome activation in RPE cells. Despite the rapid development of inflammasome research towards chronic inflammatory diseases such as AMD, there are still many unsolved questions. The biological significance of inflammasome activation in the outer retina remains controversial. On one hand, the mature product of inflammasome activation, IL-18, is hypothesized to carry out dual functions in different target cell types: as a destructive factor in GA [40] and as a protective, antiangiogenic factor in CNV [18]. On the other hand, the precise mechanisms underlying RPE demise in GA are still unclear. Does the NLRP3 inflammasome activation in RPE lead to canonical caspase-1 dependent pyroptosis [108] or necrosis or apoptosis or a combination of these mechanisms? It is well accepted that as AMD progresses, RPE cells follow a common fate:
(1) accumulation of lipofuscin; (2) enlarged cell body; (3) decrease in phagocytosis capacity; (4) formation of drusen; (5) morphological rounding; (6) hyperpigmentation; (7) hypopigmentation; (8) RPE loss [109]. In sections of human postmortem donor eyes diagnosed with GA, Sarks et al. identified double-layered hyperpigmented RPE in the GA lesion, characteristic of necrosis [110], which was further supported by the discovery that RPE cells adjacent to excessive drusen accumulation die of necrosis [111]. Consistent with this description is the finding that necrosis, particularly the released ATP, is a trigger for NLRP3 inflammasome activation [112]. Further studies are needed to understand, more fully, the combination of cell death mechanisms associated with GA. The potential involvement of an apoptotic mechanism is also supported by several studies discussed earlier in this review and by a recent transcriptome analysis on AMD eyes [113]. Furthermore, much of our knowledge of the mechanisms associated with activation and regulation of the inflammasome comes from discoveries in nonocular immune cells. Validation of these mechanisms in ocular cell types, such as RPE and photoreceptors, will be useful towards designing inflammasome-related treatment strategies for chronic inflammatory diseases of the retina, such as AMD.

\section{Conflict of Interests}

The authors declare that there is no conflict of interests regarding the publication of this paper.

\section{Acknowledgments}

The authors apologize to those whose publications were not cited due to space limitations. This work was supported by the Canadian Institutes of Health Research Grant (CIHR MOP97806) to Joanne A. Matsubara and by Vancouver General Hospital and UBC Hospital Foundation, Faculty of Medicine (UBC).

\section{References}

[1] J. Ambati, J. P. Atkinson, and B. D. Gelfand, "Immunology of age-related macular degeneration," Nature Reviews Immunology, vol. 13, no. 6, pp. 438-451, 2013.

[2] World-Health-Organization, "Age-related macular degeneration," in Prevention of Blindness and Visual ImpairmentPriority Eye Diseases, World-Health-Organization, 2014, http:// www.who.int/blindness/causes/priority/en/index7.html.

[3] Access-Economics, "The global economic cost of visual impairment," http://www.icoph.org/resources/146/The-Global-Economic-Cost-of-Visual-Impairment.html.

[4] D. S. Friedman, J. Katz, N. M. Bressler, B. Rahmani, and J. M. Tielsch, "Racial differences in the prevalence of age-related macular degeneration: the Baltimore Eye Survey," Ophthalmology, vol. 106, no. 6, pp. 1049-1055, 1999.

[5] K. J. Cruickshanks, R. Klein, and B. F. K. Klein, "Sunlight and age-related macular degeneration. The Beaver Dam Eye Study," Archives of Ophthalmology, vol. 111, no. 4, pp. 514-518, 1993.

[6] J. R. Vingerling, I. Dielemans, A. Hofman et al., "The prevalence of age-related maculopathy in the Rotterdam study," Ophthalmology, vol. 102, no. 2, pp. 205-210, 1995. 
[7] D. S. Friedman, B. J. O’Colmain, B. Muñoz et al., "Prevalence of age-related macular degeneration in the United States," Archives of Ophthalmology, vol. 122, no. 4, pp. 564-572, 2004.

[8] Age-Related Eye Disease Study Research Group, "A randomized, placebo-controlled, clinical trial of high-dose supplementation with vitamins $\mathrm{C}$ and $\mathrm{E}$, beta carotene, and zinc for agerelated macular degeneration and vision loss: AREDS report no. 8," Archives of Ophthalmology, vol. 119, no. 10, pp. 1417-1436, 2001.

[9] "Age-related eye disease study 2 research G. Lutein + zeaxanthin and omega-3 fatty acids for age-related macular degeneration: the Age-Related Eye Disease Study 2 (AREDS2) randomized clinical trial," The Journal of the American Medical Association, vol. 309, no. 19, pp. 2005-2015, 2013.

[10] E. Y. Chew, T. E. Clemons, E. Agrón et al., "Long-term effects of vitamins $C$ and $E, \beta$-carotene, and zinc on age-related macular degeneration: AREDS Report No. 35," Ophthalmology, vol. 120, no. 8, pp. 1604.e4-1611.e4, 2013.

[11] A. Woodell and B. Rohrer, "A mechanistic review of cigarette smoke and age-related macular degeneration," in Retinal Degenerative Diseases, vol. 801 of Advances in Experimental Medicine and Biology, pp. 301-307, Springer, New York, NY, USA, 2014.

[12] S. L. Fine, J. W. Berger, M. G. Maguire, and A. C. Ho, "Agerelated macular degeneration," The New England Journal of Medicine, vol. 342, no. 7, pp. 483-492, 2000.

[13] M. Boulton and P. Dayhaw-Barker, "The role of the retinal pigment epithelium: topographical variation and ageing changes," Eye, vol. 15, part 3, pp. 384-389, 2001.

[14] O. Strauss, "The retinal pigment epithelium in visual function," Physiological Reviews, vol. 85, no. 3, pp. 845-881, 2005.

[15] D. H. Anderson, R. F. Mullins, G. S. Hageman, and L. V. Johnson, "A role for local inflammation in the formation of drusen in the aging eye," American Journal of Ophthalmology, vol. 134, no. 3, pp. 411-431, 2002.

[16] M. L. Klein, F. L. Ferris III, J. Armstrong et al., "Retinal precursors and the development of geographic atrophy in agerelated macular degeneration," Ophthalmology, vol. 115, no. 6, pp. 1026-1031, 2008.

[17] W. A. Tseng, T. Thein, K. Kinnunen et al., "NLRP3 inflammasome activation in retinal pigment epithelial cells by lysosomal destabilization: implications for age-related macular degeneration," Investigative Ophthalmology and Visual Science, vol. 54, no. 1, pp. 110-120, 2013.

[18] S. L. Doyle, M. Campbell, E. Ozaki et al., "NLRP3 has a protective role in age-related macular degeneration through the induction of IL-18 by drusen components," Nature Medicine, vol. 18, no. 5, pp. 791-798, 2012.

[19] R. T. Liu, A. Wang, E. To et al., "Vinpocetine inhibits amyloid$\beta$ induced activation of NF- $\kappa \mathrm{B}, \mathrm{NLRP} 3$ inflammasome and cytokine production in retinal pigment epithelial cells," Experimental Eye Research, vol. 127, pp. 49-58, 2014.

[20] N. Kerur, Y. Hirano, V. Tarallo et al., "TLR-independent and P2X7-dependent signaling mediate Alu RNA-induced NLRP3 inflammasome activation in geographic atrophy," Investigative Ophthalmology \& Visual Science, vol. 54, no. 12, pp. 7395-7401, 2013.

[21] O. A. Anderson, A. Finkelstein, and D. T. Shima, "A2E induces IL-1ss production in retinal pigment epithelial cells via the NLRP3 inflammasome," PLoS ONE, vol. 8, no. 6, Article ID e67263, 2013.

[22] A. Kauppinen, H. Niskanen, T. Suuronen, K. Kinnunen, A. Salminen, and K. Kaarniranta, "Oxidative stress activates
NLRP3 inflammasomes in ARPE-19 cells-implications for agerelated macular degeneration (AMD)," Immunology Letters, vol. 147, no. 1-2, pp. 29-33, 2012.

[23] A. Halle, V. Hornung, G. C. Petzold et al., "The NALP3 inflammasome is involved in the innate immune response to amyloidß," Nature Immunology, vol. 9, no. 8, pp. 857-865, 2008.

[24] E. Asgari, G. Le Friec, H. Yamamoto et al., "C3a modulates IL$1 \beta$ secretion in human monocytes by regulating ATP efflux and subsequent NLRP3 inflammasome activation," Blood, vol. 122, no. 20, pp. 3473-3481, 2013.

[25] F. Laudisi, R. Spreafico, M. Evrard et al., "Cutting edge: the NLRP3 inflammasome links complement-mediated inflammation and IL-1 $\beta$ release," Journal of Immunology, vol. 191, no. 3, pp. 1006-1010, 2013.

[26] B. F. Py, M.-S. Kim, H. Vakifahmetoglu-Norberg, and J. Yuan, "Deubiquitination of NLRP3 by BRCC3 critically regulates inflammasome activity," Molecular Cell, vol. 49, no. 2, pp. 331338, 2013.

[27] M. A. Rodgers, J. W. Bowman, H. Fujita et al., "The linear ubiquitin assembly complex (LUBAC) is essential for NLRP3 inflammasome activation," The Journal of Experimental Medicine, vol. 211, no. 7, pp. 1333-1347, 2014.

[28] S. Camelo, "Potential sources and roles of adaptive immunity in age-related macular degeneration: shall we rename AMD into autoimmune macular disease?" Autoimmune Diseases, vol. 2014, Article ID 532487, 11 pages, 2014.

[29] A. Iannaccone, I. Neeli, P. Krishnamurthy et al., "Autoimmune biomarkers in age-related macular degeneration: a possible role player in disease development and progression," Advances in Experimental Medicine and Biology, vol. 723, pp. 11-16, 2012.

[30] P. Menu and J. E. Vince, "The NLRP3 inflammasome in health and disease: the good, the bad and the ugly," Clinical and Experimental Immunology, vol. 166, no. 1, pp. 1-15, 2011.

[31] M. Lamkanfi, L. V. Walle, and T.-D. Kanneganti, "Deregulated inflammasome signaling in disease," Immunological Reviews, vol. 243, no. 1, pp. 163-173, 2011.

[32] B. K. Davis, H. Wen, and J. P.-Y. Ting, "The Inflammasome NLRs in immunity, inflammation, and associated diseases," Annual Review of Immunology, vol. 29, pp. 707-735, 2011.

[33] L. Franchi, T. Eigenbrod, R. Muñoz-Planillo, and G. Nuñez, "The inflammasome: a caspase-1-activation platform that regulates immune responses and disease pathogenesis," Nature Immunology, vol. 10, no. 3, pp. 241-247, 2009.

[34] M. Lamkanfi and V. M. Dixit, "Mechanisms and functions of inflammasomes," Cell, vol. 157, no. 5, pp. 1013-1022, 2014.

[35] N. Kayagaki, S. Warming, M. Lamkanfi et al., "Non-canonical inflammasome activation targets caspase-11," Nature, vol. 479, no. 7371, pp. 117-121, 2011.

[36] K. E. Lawlor and J. E. Vince, "Ambiguities in NLRP3 inflammasome regulation: is there a role for mitochondria?" Biochimica et Biophysica Acta-General Subjects, vol. 1840, no. 4, pp. 14331440, 2014.

[37] F. S. Sutterwala, S. Haasken, and S. L. Cassel, "Mechanism of NLRP3 inflammasome activation," Annals of the New York Academy of Sciences, vol. 1319, no. 1, pp. 82-95, 2014.

[38] F. G. Bauernfeind, G. Horvath, A. Stutz et al., "Cutting edge: $\mathrm{NF}-\kappa \mathrm{B}$ activating pattern recognition and cytokine receptors license NLRP3 inflammasome activation by regulating NLRP3 expression," The Journal of Immunology, vol. 183, no. 2, pp. 787791, 2009. 
[39] S. L. Doyle, E. Ozaki, K. Brennan et al., "IL-18 attenuates experimental choroidal neovascularization as a potential therapy for wet age-related macular degeneration," Science Translational Medicine, vol. 6, no. 230, Article ID 230ra44, 2014.

[40] V. Tarallo, Y. Hirano, B. D. Gelfand et al., "DICER1 loss and Alu RNA induce age-related macular degeneration via the NLRP3 inflammasome and MyD88," Cell, vol. 149, no. 4, pp. 847-859, 2012.

[41] C. Juliana, T. Fernandes-Alnemri, S. Kang, A. Farias, F. Qin, and E. S. Alnemri, "Non-transcriptional priming and deubiquitination regulate NLRP3 inflammasome activation," Journal of Biological Chemistry, vol. 287, no. 43, pp. 36617-36622, 2012.

[42] F. di Virgilio, "The therapeutic potential of modifying inflammasomes and NOD-like receptors," Pharmacological Reviews, vol. 65, no. 3, pp. 872-905, 2013.

[43] R. Muñoz-Planillo, P. Kuffa, G. Martínez-Colón, B. L. Smith, T. M. Rajendiran, and G. Núñez, " $K^{+}$efflux is the common trigger of NLRP3 inflammasome activation by bacterial toxins and particulate matter," Immunity, vol. 38, no. 6, pp. 1142-1153, 2013.

[44] V. Hornung, F. Bauernfeind, A. Halle et al., "Silica crystals and aluminum salts activate the NALP3 inflammasome through phagosomal destabilization," Nature Immunology, vol. 9, no. 8, pp. 847-856, 2008.

[45] R. Zhou, A. S. Yazdi, P. Menu, and J. Tschopp, "A role for mitochondria in NLRP3 inflammasome activation," Nature, vol. 469, no. 7329, pp. 221-225, 2011.

[46] T. Misawa, M. Takahama, T. Kozaki et al., "Microtubule-driven spatial arrangement of mitochondria promotes activation of the NLRP3 inflammasome," Nature Immunology, vol. 14, no. 5, pp. 454-460, 2013.

[47] J. W. Crabb, M. Miyagi, X. Gu et al., "Drusen proteome analysis: an approach to the etiology of age-related macular degeneration," Proceedings of the National Academy of Sciences of the United States of America, vol. 99, no. 23, pp. 14682-14687, 2002.

[48] R. F. Mullins, S. R. Russell, D. H. Anderson, and G. S. Hageman, "Drusen associated with aging and age-related macular degeneration contain proteins common to extracellular deposits associated with atherosclerosis, elastosis, amyloidosis, and dense deposit disease," The FASEB Journal, vol. 14, no. 7, pp. 835-846, 2000.

[49] G. S. Hageman, P. J. Luthert, N. H. V. Chong, L. V. Johnson, D. H. Anderson, and R. F. Mullins, "An integrated hypothesis that considers drusen as biomarkers of immune-mediated processes at the RPE-Bruch's membrane interface in aging and age-related macular degeneration," Progress in Retinal and Eye Research, vol. 20, no. 6, pp. 705-732, 2001.

[50] L. V. Johnson, W. P. Leitner, M. K. Staples, and D. H. Anderson, "Complement activation and inflammatory processes in drusen formation and age related macular degeneration," Experimental Eye Research, vol. 73, no. 6, pp. 887-896, 2001.

[51] L. V. Johnson, W. P. Leitner, A. J. Rivest, M. K. Staples, M. J. Radeke, and D. H. Anderson, "The Alzheimer's A $\beta$-peptide is deposited at sites of complement activation in pathologic deposits associated with aging and age-related macular degeneration," Proceedings of the National Academy of Sciences of the United States of America, vol. 99, no. 18, pp. 11830-11835, 2002.

[52] M. Nozaki, B. J. Raisler, E. Sakurai et al., "Drusen complement components C3a and C5a promote choroidal neovascularization," Proceedings of the National Academy of Sciences of the United States of America, vol. 103, no. 7, pp. 2328-2333, 2006.
[53] T. Dentchev, A. H. Milam, V. M. Y. Lee, J. Q. Trojanowski, and J. L. Dunaief, "Amyloid-beta is found in drusen from some agerelated macular degeneration retinas, but not in drusen from normal retinas," Molecular Vision, vol. 9, pp. 184-190, 2003.

[54] V. Luibl, J. M. Isas, R. Kayed, C. G. Glabe, R. Langen, and J. Chen, "Drusen deposits associated with aging and age-related macular degeneration contain nonfibrillar amyloid oligomers," Journal of Clinical Investigation, vol. 116, no. 2, pp. 378-385, 2006.

[55] D. Mevorach, "Clearance of dying cells and systemic lupus erythematosus: the role of $\mathrm{Clq}$ and the complement system," Apoptosis, vol. 15, no. 9, pp. 1114-1123, 2010.

[56] D. H. Anderson, M. J. Radeke, N. B. Gallo et al., "The pivotal role of the complement system in aging and age-related macular degeneration: hypothesis re-visited," Progress in Retinal and Eye Research, vol. 29, no. 2, pp. 95-112, 2010.

[57] S. Khandhadia, V. Cipriani, J. R. W. Yates, and A. J. Lotery, "Agerelated macular degeneration and the complement system," Immunobiology, vol. 217, no. 2, pp. 127-146, 2012.

[58] K. Triantafilou, T. R. Hughes, M. Triantafilou, and P. Morgan, "The complement membrane attack complex triggers intracellular $\mathrm{Ca}^{2+}$ fluxes leading to NLRP3 inflammasome activation," Journal of Cell Science, vol. 126, no. 13, pp. 2903-2913, 2013.

[59] D. H. Anderson, K. C. Talaga, A. J. Rivest, E. Barron, G. S. Hageman, and L. V. Johnson, "Characterization of $\beta$ amyloid assemblies in drusen: the deposits associated with aging and age-related macular degeneration," Experimental Eye Research, vol. 78, no. 2, pp. 243-256, 2004.

[60] J. M. Isas, V. Luibl, L. V. Johnson et al., "Soluble and mature amyloid fibrils in drusen deposits," Investigative Ophthalmology and Visual Science, vol. 51, no. 3, pp. 1304-1310, 2010.

[61] C. Haass and D. J. Selkoe, "Soluble protein oligomers in neurodegeneration: lessons from the Alzheimer's amyloid $\beta$-peptide," Nature Reviews Molecular Cell Biology, vol. 8, no. 2, pp. 101-112, 2007.

[62] N. Iwata, S. Tsubuki, Y. Takaki et al., "Identification of the major A $\beta 1-42$-degrading catabolic pathway in brain parenchyma: suppression leads to biochemical and pathological deposition," Nature Medicine, vol. 6, no. 2, pp. 143-150, 2000.

[63] R. Madani, R. Poirier, D. P. Wolfer et al., "Lack of neprilysin suffices to generate murine amyloid-like deposits in the brain and behavioral deficit in vivo," Journal of Neuroscience Research, vol. 84, no. 8, pp. 1871-1878, 2006.

[64] R. Kayed, E. Head, J. L. Thompson et al., "Common structure of soluble amyloid oligomers implies common mechanism of pathogenesis," Science, vol. 300, no. 5618, pp. 486-489, 2003.

[65] D. M. Walsh, I. Klyubin, J. V. Fadeeva et al., "Naturally secreted oligomers of amyloid beta protein potently inhibit hippocampal long-term potentiation in vivo," Nature, vol. 416, no. 6880, pp. 535-539, 2002.

[66] W. L. Klein, G. A. Krafft, and C. E. Finch, “Targeting small A $\beta$ oligomers: the solution to an Alzheimer's disease conundrum?" Trends in Neurosciences, vol. 24, no. 4, pp. 219-224, 2001.

[67] M. D. Kirkitadze, G. Bitan, and D. B. Teplow, "Paradigm shifts in Alzheimer's disease and other neurodegenerative disorders: the emerging role of oligomeric assemblies," Journal of Neuroscience Research, vol. 69, no. 5, pp. 567-577, 2002.

[68] B. Caughey and P. T. Lansbury Jr., "Protofibrils, pores, fibrils, and neurodegeneration: separating the responsible protein aggregates from the innocent bystanders," Annual Review of Neuroscience, vol. 26, pp. 267-298, 2003. 
[69] R. T. Liu, J. Gao, S. Cao et al., "Inflammatory mediators induced by amyloid-beta in the retina and RPE in vivo: implications for inflammasome activation in age-related macular degeneration," Investigative Ophthalmology and Visual Science, vol. 54, no. 3, pp. 2225-2237, 2013.

[70] J. H. Kam, E. Lenassi, and G. Jeffery, "Viewing ageing eyes: diverse sites of amyloid beta accumulation in the ageing mouse retina and the up-regulation of macrophages," PLOS ONE, vol. 5, no. 10, Article ID e13127, 2010.

[71] T. Yoshida, K. Ohno-Matsui, S. Ichinose et al., “The potential role of amyloid $\beta$ in the pathogenesis of age-related macular degeneration," The Journal of Clinical Investigation, vol. 115, no. 10, pp. 2793-2800, 2005.

[72] K. H. Kurji, J. Z. Cui, T. Lin et al., "Microarray analysis identifies changes in inflammatory gene expression in response to amyloid- $\beta$ stimulation of cultured human retinal pigment epithelial cells," Investigative Ophthalmology and Visual Science, vol. 51, no. 2, pp. 1151-1163, 2010.

[73] M. T. Heneka, M. P. Kummer, A. Stutz et al., "NLRP3 is activated in Alzheimer's disease and contributes to pathology in APP/PS1 mice," Nature, vol. 493, no. 7434, pp. 674-678, 2013.

[74] N. Murphy, B. Grehan, and M. A. Lynch, "Glial uptake of amyloid beta induces NLRP3 inflammasome formation via cathepsin-dependent degradation of NLRP10," NeuroMolecular Medicine, vol. 16, no. 1, pp. 205-215, 2014.

[75] F. Schütt, M. Bergmann, F. G. Holz, and J. Kopitz, "Isolation of intact lysosomes from human RPE cells and effects of A2-E on the integrity of the lysosomal and other cellular membranes," Graefe's Archive for Clinical and Experimental Ophthalmology, vol. 240, no. 12, pp. 983-988, 2002.

[76] J. G. Hollyfield, V. L. Bonilha, M. E. Rayborn et al., "Oxidative damage-induced inflammation initiates age-related macular degeneration," Nature Medicine, vol. 14, no. 2, pp. 194-198, 2008.

[77] H. Kaneko, S. Dridi, V. Tarallo et al., "DICER1 deficit induces Alu RNA toxicity in age-related macular degeneration," Nature, vol. 471, no. 7338, pp. 325-332, 2011.

[78] C. W. Schmid, "Does SINE evolution preclude Alu function?" Nucleic Acids Research, vol. 26, no. 20, pp. 4541-4550, 1998.

[79] E. Bernstein, A. A. Caudy, S. M. Hammond, and G. J. Hannon, "Role for a bidentate ribonuclease in the initiation step of RNA interference," Nature, vol. 409, no. 6818, pp. 363-366, 2001.

[80] P. D. Mariner, R. D. Walters, C. A. Espinoza et al., "Human Alu RNA is a modular transacting repressor of mRNA transcription during heat shock," Molecular Cell, vol. 29, no. 4, pp. 499-509, 2008.

[81] G. Lev-Maor, R. Sorek, N. Shomron, and G. Ast, "The birth of an alternatively spliced exon: $3^{\prime}$ splice-site selection in Alu exons," Science, vol. 300, no. 5623, pp. 1288-1291, 2003.

[82] S. M. Belgnaoui, R. G. Gosden, O. J. Semmes, and A. Haoudi, "Human LINE-1 retrotransposon induces DNA damage and apoptosis in cancer cells," Cancer Cell International, vol. 6, article 13, 2006.

[83] P. Yi, W. Zhang, Z. Zhai, L. Miao, Y. Wang, and M. Wu, "Bclrambo beta, a special splicing variant with an insertion of an Alu-like cassette, promotes etoposide- and Taxol-induced cell death," FEBS Letters, vol. 534, no. 1-3, pp. 61-68, 2003.

[84] Y. Kim, V. Tarallo, N. Kerur et al., "DICER1/Alu RNA dysmetabolism induces Caspase-8-mediated cell death in agerelated macular degeneration," Proceedings of the National Academy of Sciences of the United States of America, vol. 111, no. 45, pp. 16082-16087, 2014.
[85] S. Janssens and R. Beyaert, "A universal role for MyD88 in TLR/IL-1R-mediated signaling," Trends in Biochemical Sciences, vol. 27, no. 9, pp. 474-482, 2002.

[86] P. Dupraz, S. Cottet, F. Hamburger, W. Dolci, E. Felley-Bosco, and B. Thorens, "Dominant negative MyD88 proteins inhibit interleukin- $1 \beta$ /interferon- $\gamma$-mediated induction of nuclear factor $\kappa \mathrm{B}$-dependent nitrite production and apoptosis in $\beta$ cells," The Journal of Biological Chemistry, vol. 275, no. 48, pp. 3767237678, 2000.

[87] A. O. Aliprantis, R.-B. Yang, D. S. Weiss, P. Godowski, and A. Zychlinsky, "The apoptotic signaling pathway activated by Tolllike receptor-2," The EMBO Journal, vol. 19, no. 13, pp. 33253336, 2000.

[88] G. López-Castejón and P. Pelegrín, "Current status of inflammasome blockers as anti-inflammatory drugs," Expert Opinion on Investigational Drugs, vol. 21, no. 7, pp. 995-1007, 2012.

[89] D. Arnoult, F. Soares, I. Tattoli, and S. E. Girardin, "Mitochondria in innate immunity," The EMBO Reports, vol. 12, no. 9, pp. 901-910, 2011.

[90] F.-Q. Liang and B. F. Godley, "Oxidative stress-induced mitochondrial DNA damage in human retinal pigment epithelial cells: a possible mechanism for RPE aging and age-related macular degeneration," Experimental Eye Research, vol. 76, no. 4, pp. 397-403, 2003.

[91] M. Cristina Kenney, M. Chwa, S. R. Atilano et al., "Inherited mitochondrial DNA variants can affect complement, inflammation and apoptosis pathways: insights into mitochondrialnuclear interactions," Human Molecular Genetics, vol. 23, no. 13, pp. 3537-3551, 2014.

[92] M. C. Kenney, M. Chwa, S. R. Atilano et al., "Mitochondrial DNA variants mediate energy production and expression levels for $\mathrm{CFH}, \mathrm{C} 3$ and EFEMP1 genes: implications for age-related macular degeneration," PLOS ONE, vol. 8, no. 1, Article ID e54339, 2013.

[93] D. Malik, T. Hsu, P. Falatoonzadeh et al., "Human retinal transmitochondrial cybrids with $\mathrm{J}$ or $\mathrm{H}$ mtDNA haplogroups respond differently to ultraviolet radiation: implications for retinal diseases," PloS ONE, vol. 9, no. 6, Article ID e99003, 2014.

[94] J.-M. Bruey, N. Bruey-Sedano, F. Luciano et al., "Bcl-2 and Bcl$\mathrm{X}_{L}$ regulate proinflammatory caspase- 1 activation by interaction with NALP1," Cell, vol. 129, no. 1, pp. 45-56, 2007.

[95] K. Shimada, T. R. Crother, J. Karlin et al., "Oxidized mitochondrial DNA activates the NLRP3 inflammasome during apoptosis," Immunity, vol. 36, no. 3, pp. 401-414, 2012.

[96] K. E. Lawlor, A. van Nieuwenhuijze, K. L. Parker et al., "Bcl-2 overexpression ameliorates immune complex-mediated arthritis by altering FcgammaRIIb expression and monocyte homeostasis," Journal of Leukocyte Biology, vol. 93, no. 4, pp. 585-597, 2013.

[97] K. Nakahira, J. A. Haspel, V. A. K. Rathinam et al., "Autophagy proteins regulate innate immune responses by inhibiting the release of mitochondrial DNA mediated by the NALP3 inflammasome," Nature Immunology, vol. 12, no. 3, pp. 222-230, 2011.

[98] R. Zhou, A. Tardivel, B. Thorens, I. Choi, and J. Tschopp, "Thioredoxin-interacting protein links oxidative stress to inflammasome activation," Nature Immunology, vol. 11, no. 2, pp. 136-140, 2010.

[99] F. Meissner, K. Molawi, and A. Zychlinsky, "Superoxide dismutase 1 regulates caspase-1 and endotoxic shock," Nature Immunology, vol. 9, no. 8, pp. 866-872, 2008.

[100] F. L. van de Veerdonk, S. P. Smeekens, L. A. B. Joosten et al., "Reactive oxygen species-independent activation of the IL-1 $\beta$ 
inflammasome in cells from patients with chronic granulomatous disease," Proceedings of the National Academy of Sciences of the United States of America, vol. 107, no. 7, pp. 3030-3033, 2010.

[101] F. Meissner, R. A. Seger, D. Moshous, A. Fischer, J. Reichenbach, and A. Zychlinsky, "Inflammasome activation in NADPH oxidase defective mononuclear phagocytes from patients with chronic granulomatous disease," Blood, vol. 116, no. 9, pp. 15701573, 2010.

[102] A. Rubartelli, "Redox control of $\mathrm{NLRP}_{3}$ inflammasome activation in health and disease," Journal of Leukocyte Biology, vol. 92, no. 5, pp. 951-958, 2012.

[103] K. Minton, "Inflammasomes: ubiquitin lines up for inflammasome activity," Nature Reviews Immunology, vol. 14, no. 9, pp. 580-581, 2014.

[104] S. Mirza, K. S. Plafker, C. Aston, and S. M. Plafker, "Expression and distribution of the class III ubiquitin-conjugating enzymes in the retina," Molecular Vision, vol. 16, pp. 2425-2437, 2010.

[105] X. Zhang, J. Zhou, A. F. Fernandes et al., "The proteasome: a target of oxidative damage in cultured human retina pigment epithelial cells," Investigative Ophthalmology \& Visual Science, vol. 49, no. 8, pp. 3622-3630, 2008.

[106] J. E. Ramos de Carvalhol, I. Klaassen, I. M. C. Vogels et al., "Complement factor C3a alters proteasome function in human RPE cells and in an animal model of age-related RPE degeneration," Investigative Ophthalmology and Visual Science, vol. 54, no. 10, pp. 6489-6501, 2013.

[107] J. V. Glenn, H. Mahaffy, S. Dasari et al., "Proteomic profiling of human retinal pigment epithelium exposed to an advanced glycation-modified substrate," Graefe's Archive for Clinical and Experimental Ophthalmology, vol. 250, no. 3, pp. 349-359, 2012.

[108] T. Bergsbaken, S. L. Fink, and B. T. Cookson, "Pyroptosis: host cell death and inflammation," Nature Reviews Microbiology, vol. 7, no. 2, pp. 99-109, 2009.

[109] S. B. Bressler and N. M. Bressler, "Age-related macular degeneration: non-neovascular early AMD, intermediate AMD, and geographic atrophy," in Retina, S. J. Ryan, Ed., pp. 1150-1182, Elsevier, 5th edition, 2014.

[110] J. P. Sarks, S. H. Sarks, and M. C. Killingsworth, "Evolution of geographic atrophy of the retinal pigment epithelium," Eye, vol. 2, no. 5, pp. 552-577, 1988.

[111] H. Gao and J. G. Hollyfield, "Aging of the human retina: differential loss of neurons and retinal pigment epithelial cells," Investigative Ophthalmology \& Visual Science, vol. 33, no. 1, pp. 1-17, 1992.

[112] S. S. Iyer, W. P. Pulskens, J. J. Sadler et al., "Necrotic cells trigger a sterile inflammatory response through the Nlrp3 inflammasome," Proceedings of the National Academy of Sciences of the United States of America, vol. 106, no. 48, pp. 20388-20393, 2009.

[113] A. M. Newman, N. B. Gallo, L. S. Hancox et al., "Systemslevel analysis of age-related macular degeneration reveals global biomarkers and phenotype-specific functional networks," Genome Medicine, vol. 4, no. 2, article 16, 2012. 


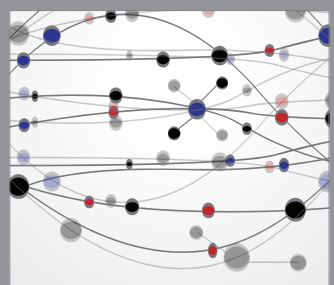

The Scientific World Journal
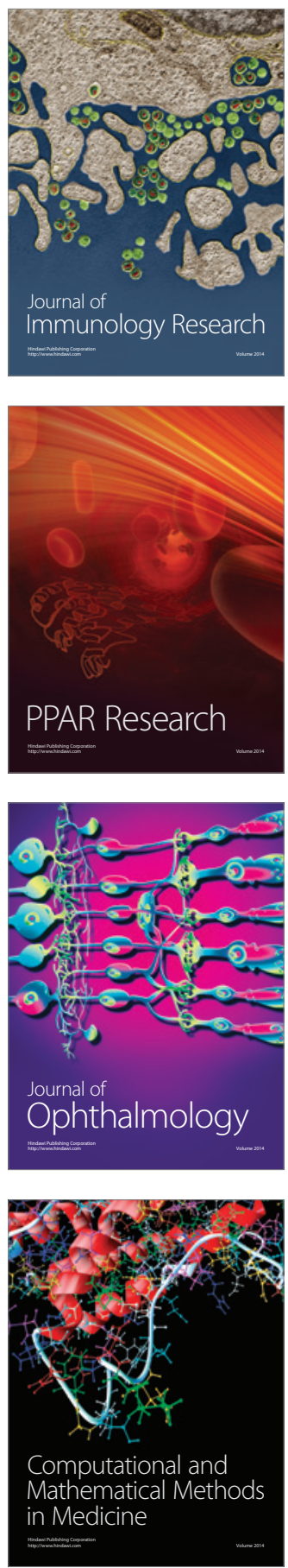

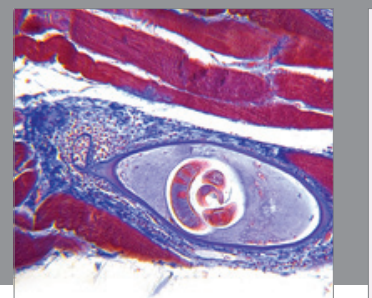

Gastroenterology

Research and Practice
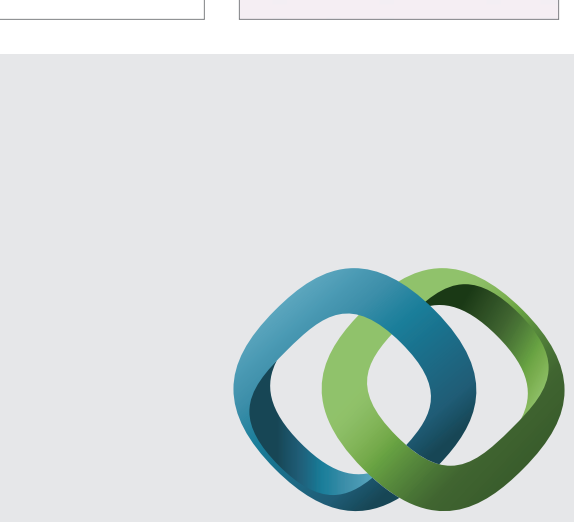

\section{Hindawi}

Submit your manuscripts at

http://www.hindawi.com
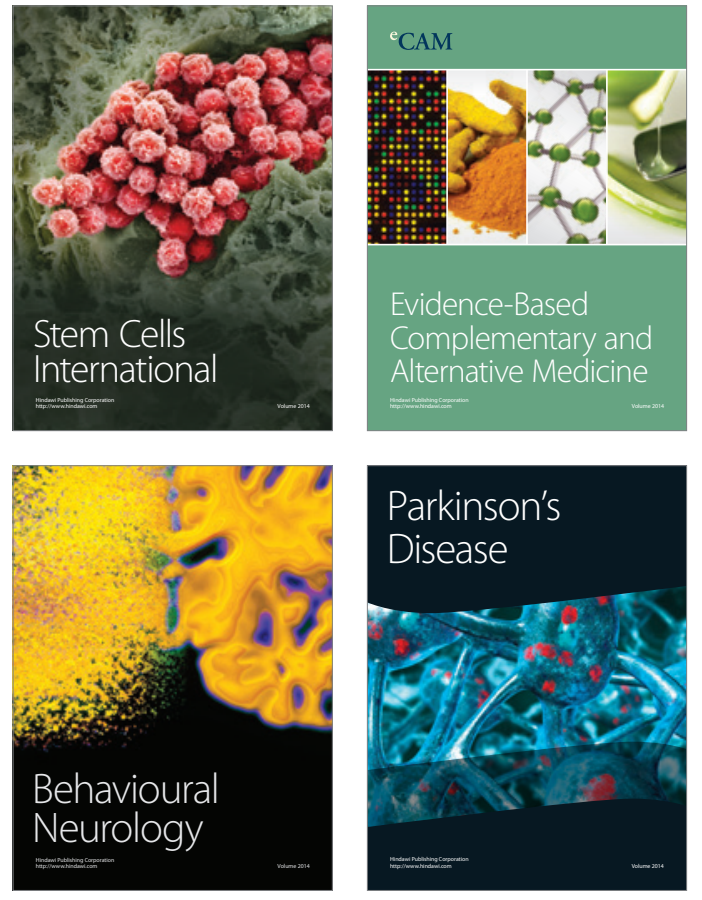
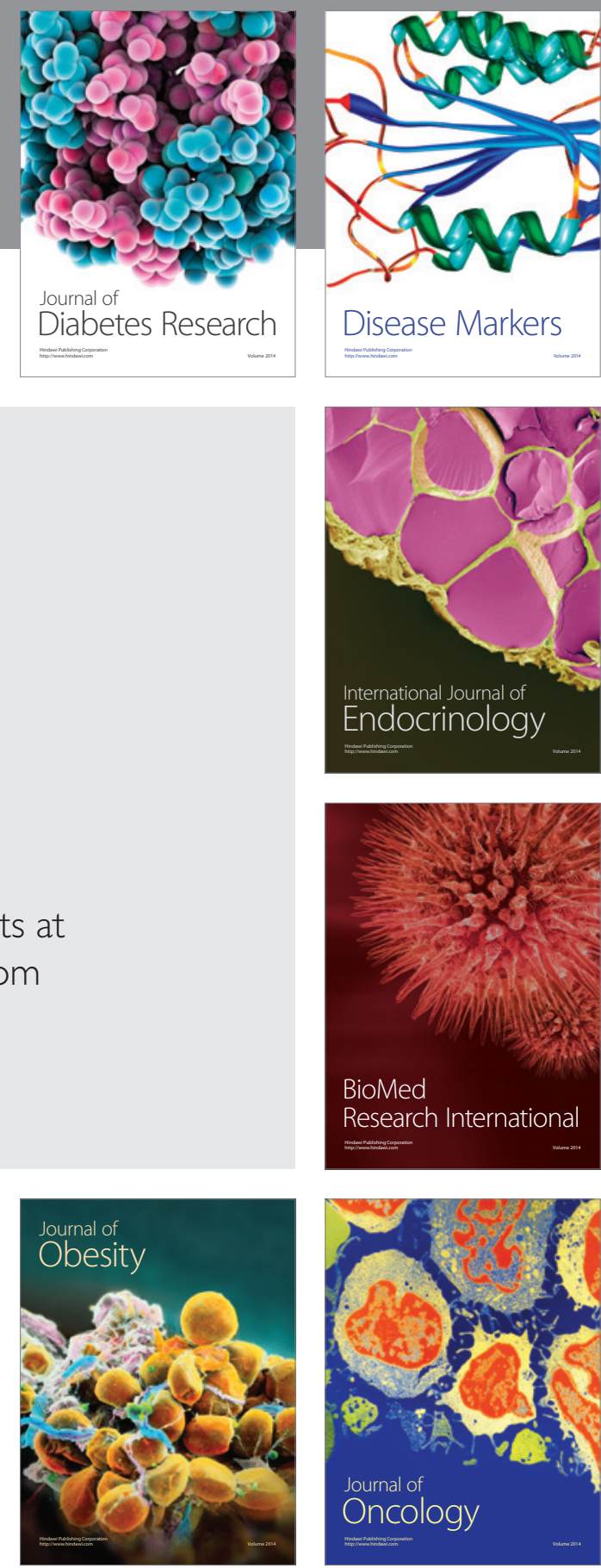

Disease Markers
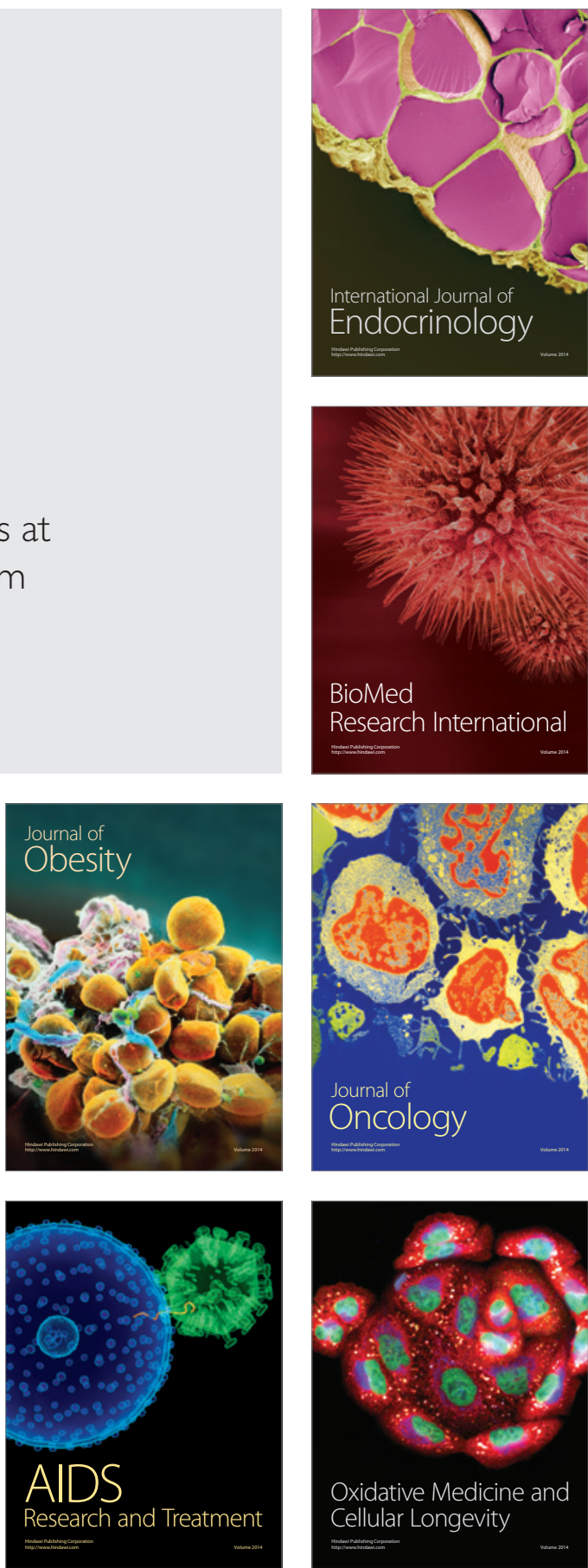